\title{
Desempenho produtivo e características de carcaça de ovinos em confinamento alimentados com rações contendo torta de mamona destoxificada em substituição ao farelo de soja
}

\author{
Roberto Cláudio Fernandes Franco Pompeu ${ }^{1}$, Magno José Duarte Cândido², Elzânia Sales \\ Pereira $^{2}$, Marco Aurélio Delmondes Bomfim ${ }^{1}$, Maria Socorro de Souza Carneiro ${ }^{2}$, Marcos \\ Cláudio Pinheiro Rogério ${ }^{1}$, Weberte Alan Sombra ${ }^{2}$, Marcos Neves Lopes ${ }^{2}$
}

\footnotetext{
${ }^{1}$ Embrapa Caprinos e Ovinos. Estrada Sobral/Groaíras, km 04, Sobral-CE, Brasil, 62010-970.

2 Departamento de Zootecnia da Universidade Federal do Ceará, Fortaleza-CE, Brasil.
}

RESUMO - Objetivou-se avaliar a influência de quatro níveis de substituição (0; 33; 67 e 100\%) do farelo de soja pela torta de mamona destoxificada em rações sobre o desempenho produtivo e as características de carcaça de ovinos mestiços de Morada Nova. Utilizaram-se 20 machos não-castrados, com peso vivo médio de 18,7 kg, em delineamento de blocos ao acaso com cinco repetições. Foram avaliados o desempenho, o peso, o rendimento e a composição regional das carcaças. A substituição do farelo de soja pela torta de mamona destoxificada não teve efeito sobre o peso vivo ao abate e o ganho de peso total durante o confinamento, entretanto teve efeito linear decrescente sobre o ganho médio diário e a conversão alimentar dos animais. Não foi observado efeito dos níveis de substituição do farelo de soja pela torta de mamona destoxificada sobre o peso vivo final, o peso vivo ao abate em jejum, o peso corporal vazio, o peso da carcaça quente e o peso da carcaça fria O rendimento de carcaça quente foi afetado pelos níveis de substituição do farelo de soja pela torta de mamona, mesmo comportamento observado para o rendimento de carcaça fria. O peso da costela e os rendimentos da costela e da paleta também foram influenciados pelos níveis de substituição do farelo de soja pela torta de mamona destoxificada. O peso e o rendimento das demais regiões, no entanto, não apresentaram diferenças entre níveis de substituição. A torta de mamona destoxificada pode ser utilizada em níveis de até $67 \%$ de substituição ao farelo de soja em dietas para ovinos.

Palavras-chave: borregos, rendimento de carcaça, Ricinus communis, subproduto do biodiesel

\section{Performance and carcass traits of sheep in feedlot and fed diets containing detoxified castor cake replacing soybean meal}

\begin{abstract}
The objective of this study was to evaluate the influence of four substitution levels (0;33; 67 and $100 \%)$ of soybean meal by detoxified castor cake on performance and carcass characteristics of 20 non-castrated male crossbred Morada Nova lambs, with mean body weight of $18.7 \mathrm{~kg}$, in a randomized blocks design with four treatments and five replicates Performance, carcass weight, carcass yield and relative composition of the commercial cuts were evaluated. The substitution levels of soybean meal by detoxified castor cake had no effect on final live weight or total weight gain in feedlot, but it caused decreasing linear effect on average daily gain and feed conversion ratio was observed. There was no effect of the substitution levels of soybean meal by detoxified castor cake on final body weight, live weight at fasting, empty body weight, hot carcass weight or cold carcass weight. The hot carcass yield was affected by substitution levels; the same behavior was observed for cold carcass yield. Rib weight and yield and shoulders yield had linear decrease of substitution levels of soybean meal by detoxified castor cake, whereas weight and yield of other regions did not present any effect for the substitution levels. Detoxified castor cake can be utilized in levels of up to $67 \%$ in substitution of the soybean meal in sheep diets.
\end{abstract}

Key Words: biodiesel byproducts, carcass yield, lambs, Ricinus communis

\section{Introdução}

Na Região Nordeste do Brasil, a exploração de ovinos tem grande importância socioeconômica para a produção de carne, especialmente por ser fonte de proteína de alto valor biológico. O confinamento de ovinos tem despertado o interesse na intensificação do sistema de produção por reduzir as perdas de animais jovens por deficiências nutricionais e infestações parasitárias, manter a regularidade da oferta de carne e peles durante o ano e obter retorno mais rápido do capital investido por meio da redução da idade ao abate (Medeiros et al., 2007). 
A alimentação é um dos fatores que mais oneram os sistemas de produção intensivos, tornando necessárias fontes alimentares de bom valor nutritivo e de baixo custo. Nesse contexto, a torta de mamona, subproduto da produção de biodiesel e oriunda da prensagem da semente a elevadas temperaturas, pode ser uma fonte proteica promissora para diminuir os custos de produção em sistemas intensivos e semi-intensivos de criação, já que existe a necessidade da destinação dos subprodutos gerados pelas indústrias com a finalidade de prevenir danos ao meio ambiente.

A torta de mamona é obtida por prensagem a quente da amêndoa, sem a utilização de produtos químicos, e tem rendimento de $50 \%$. O óleo resultante pode ser utilizado na indústria após sua extração e o resíduo da torta pode ser aproveitado na alimentação animal. Contudo, a presença de ricina na amêndoa, uma das mais potentes proteínas citotóxicas já conhecidas no reino vegetal, provoca graves perturbações digestivas e pode levar à morte se ingerida em doses letais (Tokarnia et al., 2000; Aslani et al., 2006), e isso é um dos principais entraves da utilização de torta de mamona na alimentação animal. De acordo com Tokarnia et al. (2000), a dose letal das sementes moídas de Ricinus communis administradas por via oral em administração única para ovinos é de $1,25 \mathrm{~g} / \mathrm{kg}$, enquanto para caprinos é de $5,5 \mathrm{~g} / \mathrm{kg}$.

Em recente investigação, Anandan et al. (2005) compararam a eficácia de diferentes métodos de destoxificação da ricina do farelo de mamona. Entre os métodos avaliados, a autoclavagem com pressão de $1,23 \mathrm{kgf} / \mathrm{cm}^{2}$ ou $15 \mathrm{psi}$ a $123^{\circ} \mathrm{C}$ durante 60 minutos eliminou complemente a toxina.

Diante do exposto, realizou-se este trabalho com o objetivo de avaliar a influência de quatro níveis de substituição do farelo de soja pela torta de mamona destoxificada sobre o desempenho produtivo e as características da carcaça de ovinos mestiços de Morada Nova.

\section{Material e Métodos}

O trabalho foi conduzido no Núcleo de Ensino e Estudos em Forragicultura-NEEF/DZ/CCA/UFC (www.neef.ufc.br) em Fortaleza, Ceará, no período de novembro de 2008 a março de 2009. O município de Fortaleza situa-se na zona litorânea a 15,49 m de altitude, $30^{\circ} 43^{\prime} 02^{\prime \prime}$ de latitude sul e $38^{\circ} 32$ '35" de longitude oeste.

Foram avaliados quatro níveis de substituição $(0,33,67$ e 100\%) do farelo de soja pela torta de mamona destoxificada em rações para borregos em delineamento de blocos casualizados com cinco repetições (borregos), considerando o feno de capim-tifton-85 como volumoso.
A torta de mamona foi obtida na Fazenda Normal, pelo Instituto de Desenvolvimento Sustentável e Energias Renováveis (IDER), no município de Quixeramobim, Ceará, a partir da extração mecânica (prensagem) do óleo da semente, utilizando temperaturas entre 90 e $100{ }^{\circ} \mathrm{C}$, e destoxificada na Embrapa - Agroindústria Tropical, pelo método de autoclavagem (autoclave Sercon, modelo HAE23) com pressão de $1,23 \mathrm{~kg} / \mathrm{cm}^{2}(15 \mathrm{psi})$ a $123^{\circ} \mathrm{C}$ por 60 minutos, conforme Anandan et al. (2005).

As unidades experimentais foram adquiridas do próprio rebanho do Núcleo de Ensino e Estudos em Forragicultura (NEEF) e constaram de 20 ovinos mestiços ( $1 / 2$ Morada Nova variedade vermelha $\times 1 / 2$ sem padrão racial definido), machos

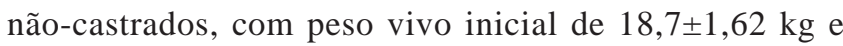
aproximadamente 6,5 meses de idade. Antes do início do experimento, os animais foram vermifugados e receberam suplementação de vitaminas A, D e E injetável por via subcutânea e foram alojados em baias individuais com aproximadamente $1,0 \mathrm{~m}^{2}$, providas de comedouros e bebedouros, dispostas em área coberta.

As rações experimentais foram formuladas com base nas recomendações do NRC (2007), sendo isoproteicas e isoenergéticas e com relação volumoso:concentrado de 50:50 (Tabelas 1 e 2). A ração experimental foi fornecida diariamente em duas refeições, uma às $8 \mathrm{~h}$ ( $50 \%$ do total ofertado ao dia) e outra às $16 \mathrm{~h}$ (50\% do total ofertado ao dia), e as sobras foram coletadas no dia seguinte e pesadas, para que fossem mantidas em torno de $15 \%$.

Os animais foram confinados em baias individuais de madeira providas de comedouros e bebedouros e pesados semanalmente durante todo o período experimental, composto de 14 dias de adaptação e coleta de dados. As pesagens foram realizadas até os animais atingirem o peso de abate (aproximadamente $30 \mathrm{~kg}$ ). Amostragens dos alimentos fornecidos e das sobras foram realizadas diariamente pela manhã no momento da pesagem do alimento que cada animal recebeu durante todo o período de coleta dos dados. As amostras foram acondicionadas em sacos plásticos identificados e armazenadas a $-10^{\circ} \mathrm{C}$. Ao final do experimento, as amostras referentes a cada animal foram descongeladas e homogeneizadas, sendo retirada uma amostra de aproximadamente $300 \mathrm{~g}$, que foi levada ao Laboratório de Nutrição Animal da Universidade Federal do Ceará, pesada e colocada em estufa de ventilação forçada por três dias sob temperatura de $60{ }^{\circ} \mathrm{C}$. Em seguida, determinaram-se os teores de matéria seca (MS), proteína bruta (PB), fibra em detergente neutro corrigida para cinzas e proteína (FDNcp), fibra em detergente ácido (FDA), extrato etéreo (EE) e cinzas (CINZAS) nas amostras conforme técnicas descritas em Silva \& Queiroz (2002). Os carboidratos 
Tabela 1 - Composição centesimal dos ingredientes e da ração total contendo torta de mamona destoxificada em substituição ao farelo de

\begin{tabular}{|c|c|c|c|c|}
\hline \multirow[t]{2}{*}{ Ingrediente } & \multicolumn{4}{|c|}{ Nível de substituição } \\
\hline & $0 \%$ TMD & $33 \%$ TMD & 67\% TMD & $100 \%$ TMD \\
\hline Feno de capim-tifton-85 & 50,1 & 50,4 & 50,6 & 50,5 \\
\hline Farelo de milho & 33,6 & 32,5 & 31,7 & 30,6 \\
\hline Farelo de soja & 14,2 & 10,3 & 5,31 & 0,00 \\
\hline Torta de mamona destoxificada & 0,00 & 5,09 & 10,8 & 16,8 \\
\hline Ureia & 0,23 & 0,32 & 0,50 & 0,68 \\
\hline Sulfato de amônio & 0,10 & 0,15 & 0,23 & 0,31 \\
\hline Sal comum & 0,50 & 0,50 & 0,51 & 0,50 \\
\hline Calcário & 0,53 & 0,27 & 0,00 & 0,00 \\
\hline Fosfato bicálcico & 0,29 & 0,08 & 0,00 & 0,24 \\
\hline Premix mineral ${ }^{1}$ & 0,40 & 0,40 & 0,40 & 0,40 \\
\hline
\end{tabular}

TMD - torta de mamona destoxificada.

${ }^{1}$ Composição: fósforo - 65,0 g; cálcio - 160,0 g; enxofre - 15,0 g; magnésio - 6,5 g; sódio - 150,0 g; cobalto - 0,125 g; zinco - 4,5 g; ferro - 1,7 g; manganês - 4,5 g; iodo - 0,06 g; selênio - 0,03 g; flúor - 0,95 g; veículo - $1.000 \mathrm{~g}$.

Tabela 2 - Composição químico-bromatológica dos ingredientes e das dietas experimentais

\begin{tabular}{|c|c|c|c|c|c|c|c|c|}
\hline$\overline{\text { Item }}$ & \multicolumn{4}{|c|}{ Ingrediente } & \multicolumn{4}{|c|}{ Dieta total $(\% \mathrm{MS})^{2}$} \\
\hline Matéria seca (\%MN) & 91,4 & 89,8 & 88,9 & 90,6 & 89,3 & 89,9 & 90,6 & 90,8 \\
\hline Proteína bruta (\%MS) & 5,99 & 10,0 & 48,1 & 30,2 & 13,9 & 13,7 & 13,4 & 13,1 \\
\hline Fibra em detergente neutro (\%MS) & 82,1 & 16,2 & 13,3 & 47,9 & 48,5 & 50,4 & 52,5 & 54,5 \\
\hline $\begin{array}{l}\text { Fibra em detergente neutro corrigida para } \\
\text { cinzas e proteína }(\% \mathrm{MS})\end{array}$ & 79,8 & 13,7 & 12,0 & 45,3 & 46,3 & 48,2 & 50,2 & 52,1 \\
\hline Extrato etéreo (\%MS) & 1,32 & 5,91 & 1,80 & 6,10 & 2,90 & 3,08 & 3,30 & 3,50 \\
\hline Celulose (\%MS) & 32,6 & 2,72 & 4,71 & 33,3 & 17,9 & 19,5 & 21,2 & 22,9 \\
\hline Hemicelulose (\%MS) & 36,8 & 9,79 & 2,30 & 5,03 & 22,1 & 22,2 & 22,4 & 22,4 \\
\hline Lignina (\%MS) & 6,64 & 0,61 & 1,14 & 3,42 & 3,70 & 3,83 & 3,98 & 4,11 \\
\hline Nitrogênio insolúvel em detergente neutro (\%NT) & 69,9 & 11,2 & 5,00 & 15,7 & 39,5 & 40,2 & 40,8 & 41,3 \\
\hline Nitrogênio insolúvel em detergente ácido (\%NT) & 36,6 & 2,69 & 3,65 & 13,3 & 19,8 & 20,4 & 21,0 & 21,5 \\
\hline
\end{tabular}

${ }^{1}$ NDT estimado (NRC, 2001).

2 Porcentagem de torta de mamona destoxificada na ração concentrada, com base na MS.

totais (CT) foram obtidos a partir da equação 100 - (\%PB + \%EE + \%CINZAS), conforme descrito por Sniffen et al. (1992). Já os valores de carboidratos não-fibrosos (CNF) foram obtidos por diferença entre carboidratos totais e FDNcp.

Os valores de nutrientes digestíveis totais (NDT) dos alimentos isoladamente foram estimados conforme o National Research Council (2001), utilizando-se as seguintes equações: $\mathrm{CNFVD}=0,98 \times\{100-[(\mathrm{FDN}-\mathrm{PBIDN})+\mathrm{PB}+\mathrm{EE}+$ Cinzas $]\}$ $\mathrm{PBVD}=[1-(0,4 \times(\mathrm{PBIDA} / \mathrm{PB}))] \times \mathrm{PB}$

$\mathrm{AGVD}=\mathrm{EE}-1$

$\mathrm{FDNVD}=0,75 \times[(\mathrm{FDN}-\mathrm{PBIDN})-\mathrm{L}] \times[1(\mathrm{~L} /((\mathrm{FDN}-\mathrm{PBIDN})$ $\times \mathrm{EXP} \times 0,667))]$.

$\mathrm{NDT1}_{\mathrm{X}}(\%)=\mathrm{CNFVD}+\mathrm{PBVD}+(\mathrm{AGVD} \times 2,25)+\mathrm{FDNVD}-7$, em que: $N D T 1_{X}=$ nutrientes digestíveis totais para manutenção; CNFVD = carboidratos não-fibrosos verdadeiramente digestíveis; $\mathrm{PBVD}=$ proteína bruta verdadeiramente digestível; AGVD = ácidos graxos verdadeiramente digestíveis; FDNVD = fibra em detergente neutro verdadeiramente digestível; FDN = fibra em detergente neutro; $\mathrm{EE}$ = extrato etéreo; $\mathrm{L}$ = lignina em detergente ácido; $\mathrm{PB}$ = proteína bruta; $\mathrm{PBIDN}$ = proteína bruta insolúvel em detergente neutro; PBIDA = proteína bruta insolúvel em detergente ácido.

O cálculo do valor de NDT das dietas experimentais foi estimado a partir da seguinte equação: NDT = PBdigestível + FDNdigestível + (EEdigestível × 2,25) + CNFdigestível (Sniffen et al., 1992).

Foram avaliados o ganho de peso total (GPT), o ganho de peso médio diário (GMD), o número de dias para o animal ganhar 12 kg (D12) e a conversão alimentar (CA). A pesagem dos animais foi realizada a cada sete dias e o ganho de peso total calculado pela diferença entre a última e a primeira pesagem. O ganho médio diário (GMD) foi calculado tomando-se o peso inicial e final de cada semana, dividido 
pelo tempo transcorrido. O número de dias necessários para os animais ganharem $12 \mathrm{~kg}$ (D12) foi estimado dividindo-se essa quantidade em gramas pelo GMD (Pompeu et al., 2009). A conversão alimentar foi obtida dividindo-se o consumo médio diário de MS da ração de cada ovino pelo seu respectivo GMD.

Quando a média de peso dos animais em cada tratamento atingiu $30 \mathrm{~kg}$, os animais foram pesados e submetidos a jejum prévio de 16 e 14 horas para dietas sólida e líquida, respectivamente. Previamente ao abate, os animais foram novamente pesados para obtenção do peso vivo ao abate em jejum (PVAJ).

No momento do abate, os animais foram insensibilizados por atordoamento na região atlanto-occipital, seguido de sangria por três minutos, por secção da carótida e da jugular. Após o abate, realizaram-se a esfola, evisceração, retirada da cabeça, patas e órgãos genitais. Sequencialmente, as carcaças foram pesadas para obtenção do peso da carcaça quente (PCQ) e envolvidas por sacos plásticos identificados por animal/tratamento e transportadas para câmara frigorífica a $4{ }^{\circ} \mathrm{C}$, onde foram mantidas por 24 horas, sendo novamente pesadas para a obtenção do peso da carcaça fria (PCF). O trato gastrintestinal foi esvaziado e pesado antes e depois do procedimento para obtenção do peso corporal vazio (PCVZ = PCQ - conteúdo gastrintestinal), visando determinar o rendimento verdadeiro ou biológico (RB), obtido pela relação entre o peso da carcaça quente e o peso corporal vazio (Sañudo \& Sierra, 1986). Para determinação do rendimento de carcaça quente (RCQ), rendimento de carcaça fria (RCF) e rendimento biológico (RB), foram utilizadas as fórmulas que se seguem: RCQ = $(\mathrm{PCQ} / \mathrm{PVAJ}) \times 100 ; \mathrm{RCF}=(\mathrm{PCF} / \mathrm{PVAJ}) \times 100 ; \mathrm{RB}=(\mathrm{PCQ} /$ PCVZ) $\times 100$, respectivamente (Silva Sobrinho, 2001).

Para obtenção dos cortes, a carcaça foi dividida após a retirada do pescoço em duas partes simétricas por corte longitudinal da coluna vertebral. A meia-carcaça esquerda foi dividida em seis regiões anatômicas, denominadas cortes comerciais: perna, lombo, paleta, peito, costela e fraldinha (Monte et al., 2009). O lombo foi dividido em anterior e posterior, considerando que esses cortes são comercializados separadamente (Figura 1). Os cortes foram pesados e congelados para posteriores análises.

Os limites anatômicos entre os cortes foram feitos conforme descrito por Gatty (1986) para a espécie caprina: perna (compreendeu a região sacral e os segmentos anatômicos: cíngulo pélvico, coxa e perna, com o corte transversal passando entre a articulação da última vértebra lombar e a primeira sacral na posição média dos ossos do

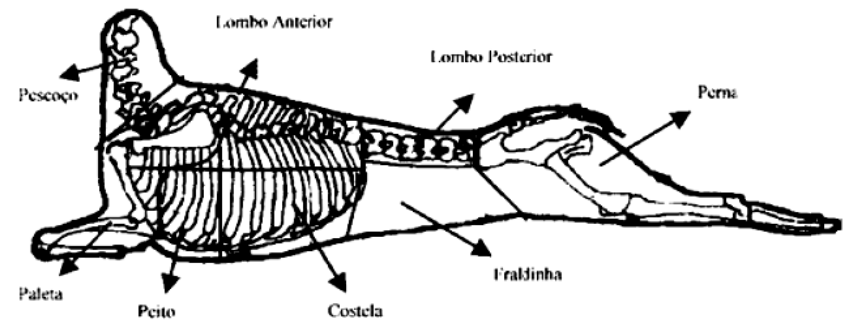

Adaptado de Monte et al. (2009).

Figura 1 - Sistema de cortes da carcaça de ovinos.

tarso, seccionando os ligamentos supraespinhoso lombo sacro, interespinhoso e o ligamento longitudinal ventral e dorsal); lombo anterior (base óssea que compreendeu da primeira à última vértebra torácica, delimitada pela parte dorsal da região lateral do tórax, englobando aproximadamente $7,0 \mathrm{~cm}$ de costela); lombo posterior (corte compreendido da primeira à última vértebra lombar, com corte passando entre a última vértebra torácica e a primeira lombar, e outro entre a última lombar e a primeira sacral); paleta (corte compreendido entre as regiões do cíngulo escapular, braço e antebraço, sendo a base óssea formada pela escápula, úmero, rádio, ulna e osso do carpo). O corte da paleta foi obtido por seç̧ão da região axilar e dos músculos que unem a escápula e o úmero na parte ventral do tórax; costela e peito (corte que corresponde à região inferior da lateral do tórax, seccionada completamente entre a $5 \underline{a}$ e a $6 \underline{a}$ costela) e pescoço (obtido pelo corte entre o osso occipital e o atlas, primeira vértebra cervical, e um segundo corte oblíquo entre a 6무 e a 7aㅡ vértebras cervicais, em direção à ponta do esterno, terminando na borda inferior do pescoço).

A perna e o lombo (anterior e posterior) foram considerados cortes de primeira, a paleta como de segunda e os demais, de terceira categoria, seguindo o sistema de classificação de cortes adotados por Yamamoto et al. (2004) e Monte et al. (2009). Para cálculo do rendimento do pescoço, o peso deste corte foi dividido por dois e o rendimento dos cortes foi calculado pelo peso de cada corte em relação ao peso da carcaça fria (PCF).

Os dados foram submetidos à análise de variância e de regressão. A escolha dos modelos baseou-se na significância dos coeficientes linear ou quadrático, utilizando-se o teste "t", de Student, a 5\% de probabilidade, e no coeficiente de determinação. Como auxílio às análises estatísticas, utilizou-se o procedimento GLM, do pacote computacional SAS (Statistical Analyses System, version 9.0). 


\section{Resultados e Discussão}

Não houve efeito $(\mathrm{P}>0,05)$ dos níveis de substituição do farelo de soja (FS) pela torta de mamona destoxificada (TMD) sobre o peso vivo ao abate (PVf) e o ganho de peso total (GPT) durante o confinamento, o qual foi considerado satisfatório, visto que ovinos mestiços de Morada Nova em geral entram na fase de terminação com peso de 18 a $20 \mathrm{~kg}$ e são abatidos quando atingem aproximadamente $30 \mathrm{~kg}$ (Tabela 3).

Observou-se redução linear $(\mathrm{P}<0,05)$ no ganho de peso médio diário (GMD) dos ovinos com a elevação dos níveis de substituição do farelo de soja pela torta de mamona. O ganho médio diário foi estimado em 197 e 130 g/dia para os animais alimentados com as dietas contendo 0 e $100 \%$ de torna de mamona, respectivamente. A cada 1\% de substituição do farelo de soja pela torta de mamona, estimaram-se decréscimos de 0,62 g/dia no GMD. Apesar de as dietas terem sido formuladas para ser isoproteicas e isoenergéticas, a redução do GMD com a elevação do nível de substituição deveu-se à diminuição no consumo de nutrientes, já que o desempenho animal depende da ingestão de nutrientes, que, por sua vez, é determinada pela quantidade de matéria seca ingerida.

O menor GMD dos animais alimentados nos maiores níveis de substituição deveu-se à menor palatabilidade da torta de mamona em relação ao farelo de soja, devido à maior quantidade de fragmentos de semente de mamona, elevando a quantidade de extrato etéreo na dieta e, consequentemente, a proporção de ácido ricinoleico, que representa mais de 90\% do total de ácidos graxos da torta de mamona (Moshkin, 1986). Além disso, é possível que a hidroxila presente no carbono 12 do ácido ricinoleico afete negativamente o metabolismo microbiano (Oliveira et al., 2010), o que pode ter repercutido na redução de sua palatabilidade, induzindo os animais a rejeitar o concentrado nos maiores níveis de substituição. Além disso, é possível também que tenha havido oxidação das gorduras da TMD durante a autoclavagem, contribuindo para a rejeição desse alimento pelos animais.
Vale ressaltar que, embora o nível proteico entre as dietas tenha sido próximo, a baixa degradabilidade da PB na torta de mamona destoxificada, de 58,7\% em 72 horas de incubação, devido ao elevado teor de proteína bruta insolúvel em detergente ácido (43,8\% de PIDA em relação à $\mathrm{PB}$ ), pode ter limitado a ação microbiana no ambiente ruminal (Gomes, 2007). Valor superior ao observado neste trabalho foi relatado por Vieira (2009), que, em pesquisa com ovinos mestiços de Morada Nova alimentados com dietas formuladas com diferentes níveis de farelo de mamona destoxificada em substituição ao farelo de soja, relatou GMD de 185 g/dia, com 100\% de substituição. Apesar da semelhança no teor de PB das rações de ambas as pesquisas, o maior ganho observado pelo autor deveu-se ao elevado teor de PB do farelo de mamona destoxificado $(50,9 \%)$, associado à alta degradabilidade da PB, de 86,8\% em 72 horas de incubação (Gomes, 2007).

O número de dias para os ovinos ganharem 12 kg (D12) elevou-se linearmente $(\mathrm{P}<0,05)$ de acordo com o nível de torta de mamona na dieta, antecipando o abate dos ovinos em 33 dias, no nível de $100 \%$ de farelo de soja em relação ao nível de $100 \%$ de torta de mamona. Para cada 1\% do nível de substituição do farelo de soja pela torta de mamona, houve acréscimo de 0,35 dia para os animais ganharem $12 \mathrm{~kg}$. Em média, os ovinos mestiços de Morada Nova entram na fase de terminação com aproximadamente $18 \mathrm{~kg}$ de peso vivo e são comercializados quando apresentam entre 30 e $32 \mathrm{~kg}$. Portanto, quanto menor o tempo de ocupação dos animais no confinamento, maior o número de animais terminados por ano e menor o custo de produção, proporcionando maior rotatividade de animais no confinamento e amortizando mais rapidamente as despesas com instalações e alimentação. Apesar de o ganho de peso total durante o confinamento ter sido semelhante entre os níveis de substituição ( \pm 13,0 kg), menores períodos de confinamento reduzem a idade ao abate e favorecem as carcaças em termos qualiquantitativos.

A substituição do farelo de soja pela torta de mamona destoxificada causou efeito linear crescente $(\mathrm{P}<0,05)$, piorando a conversão alimentar das dietas estudadas,

Tabela 3 - Desempenho produtivo de ovinos mestiços Morada Nova $\times$ SPRD alimentados com dietas contendo torta de mamona destoxificada em substituição ao farelo de soja

\begin{tabular}{|c|c|c|c|c|c|c|c|}
\hline \multirow[t]{2}{*}{ Variável } & \multicolumn{4}{|c|}{ Nível de substituição (\%MS) } & \multirow[t]{2}{*}{ CV (\%) } & \multirow[t]{2}{*}{ Equação } & \multirow[t]{2}{*}{$\mathrm{P} \leq$} \\
\hline & 0 & 33 & 67 & 100 & & & \\
\hline Peso vivo inicial (kg) & 19,8 & 18,9 & 18,2 & 18,0 & - & - & - \\
\hline Peso vivo ao abate (kg) & 30,3 & 29,6 & 30,4 & 30,4 & 10,5 & $\hat{Y}=30,2 \pm 10,2$ & - \\
\hline Ganho de peso total (kg) & 12,9 & 12,2 & 12,9 & 13,3 & 18,2 & $\hat{Y}=12,9 \pm 2,3$ & - \\
\hline Ganho de peso médio diário (g/dia) & 197 & 160 & 155 & 130 & 16,7 & $\hat{Y}=192-0,62 \mathrm{TMD} ; \mathrm{r}^{2}=0,48$ & 0,001 \\
\hline Número de dias para ganharem 12 kg (dias) & 61 & 77 & 78 & 100 & 23,4 & $\hat{Y}=61,1+0,35 T M D ; r^{2}=0,39$ & 0,005 \\
\hline Conversão alimentar (kg MS cons/kg PV ganho) & 4,92 & 5,50 & 5,59 & 6,38 & 7,75 & $\hat{Y}=4,92+0,015 \mathrm{TMD} ; \mathrm{r}^{2}=0,62$ & 0,001 \\
\hline
\end{tabular}


estimada em 4,92 e 6,42 kg MS consumida/kg PV ganho para os ovinos alimentados com 0 e $100 \%$ de TMD, respectivamente. Para cada 1 unidade percentual de substituição do farelo de soja pela torta de mamona, ocorreu aumento de 0,015 g de matéria seca consumida para cada grama de aumento no ganho de peso (Tabela 3). A possível explicação para essa pior conversão alimentar seria a redução no ganho médio diário com o aumento da substituição do farelo de soja pela torta de mamona. Medeiros et al. (2007), em pesquisa com ovinos da raça Morada Nova em confinamento e alimentados com diferentes níveis de concentrado, observaram conversão alimentar de 7,46 kg MS consumida/kg PV ganho quando a relação volumoso:concentrado era de 50:50, resultado pior que o verificado neste trabalho.

Ovinos da raça Morada Nova normalmente são mantidos em ambiente semiárido, em pastagens de caatinga nativa, e apresentam baixos índices produtivos, principalmente quando há escassez de alimento nas épocas secas (Medeiros et al., 2007). Por outro lado, nas condições intensivas deste experimento, os animais não alimentados com torta de mamona destoxificada atingiram ganhos e conversão alimentar próximos (192 g/dia e 4,92 kg MS cons/kg PV ganho) ao de algumas raças mais especializadas, como as verificadas por Furusho Garcia et al. (2001), que observaram GMD médio de 235 g/dia, com conversão alimentar de 4,28 kg MS cons/kg PV ganho, evidenciando seu potencial para ganho de peso.

Não foi observado efeito $(\mathrm{P}>0,05)$ dos níveis de substituição do farelo de soja (FS) pela torta de mamona destoxificada (TMD) sobre o peso vivo ao abate em jejum, peso de corpo vazio, peso de carcaça quente e peso de carcaça fria (Tabela 4). Esse resultado pode ser atribuído ao critério de peso estabelecido para o abate, de aproximadamente de $30 \mathrm{~kg}$ PV. Esses resultados confirmam a lei da harmonia anatômica (Boccard \& Dumont, 1960) em carcaças com pesos similares, onde praticamente todas as regiões corporais se encontram em proporções semelhantes, qualquer que seja a conformação considerada.
Esses dados são semelhantes aos relatados por Medeiros et al. (2007), em pesquisa com ovinos da raça Morada Nova alimentados com diferentes níveis de concentrado na dieta e abatidos aos $30 \mathrm{~kg}$ de PV. O peso ótimo de abate, principalmente de ovinos deslanados, deve ser definido para cada raça considerando a preferência dos consumidores. Zapata et al. (2001) reportaram que o peso de abate na Região Nordeste tem sido próximo dos $30 \mathrm{~kg}$, que resulta em carcaça com 12,5 a 14,0 kg, faixa em que se situaram os valores encontrados neste trabalho. O peso da carcaça é influenciado pela velocidade de crescimento, pela idade ao abate, pelo plano nutricional, entre outros, e constitui importante fator na estimativa de seu rendimento.

O rendimento de carcaça quente (RCQ) foi afetado $(\mathrm{P}<0,05)$ pelos níveis de substituição, apresentando resposta linear decrescente estimada, respectivamente, em 48,8 e 46,8\% para os níveis 0 e $100 \%$ de substituição do farelo de soja (FS) pela torta de mamona destoxificada (TMD). O mesmo comportamento foi observado para o rendimento de carcaça fria (RCF), que apresentou redução de 0,02 ponto percentual a cada $1 \%$ de substituição do farelo de soja pela torta de mamona. Mesmo no maior nível de substituição do farelo de soja pela torta de mamona, os rendimentos de carcaça quente e fria e o rendimento biológico foram superiores aos preconizados por Silva Sobrinho (2001), que descreveu rendimentos de carcaça quente de $46 \%$, carcaça fria de $44,5 \%$ e rendimento biológico de $53 \%$. Segundo Silva \& Pires (2000), os maiores rendimentos de carcaça ovina são encontrados para os animais mais jovens, devido ao aumento do trato gastrintestinal com o avançar da idade, que diminui o rendimento das carcaças. Vale ressaltar que a valorização da carcaça ovina depende da relação entre peso corporal e idade, onde se buscam maiores pesos a menores idades.

Os rendimentos de carcaça quente e carcaça fria obtidos neste trabalho foram superiores aos encontrados por Vieira et al. (2010) em carcaças de cordeiros mestiços de Morada Nova abatidos próximos aos $30 \mathrm{~kg}$ de peso vivo e também aos 44,1 e $42,8 \%$, respectivamente, observados por

Tabela 4 - Características de carcaça e rendimento dos cortes de ovinos mestiços Morada Nova × SPRD alimentados com rações contendo torta de mamona destoxificada em substituição ao farelo de soja

\begin{tabular}{lccccccc}
\hline Parâmetro & \multicolumn{3}{c}{ Nível de substituição (\%MS) } & CV (\%) & Equação & \\
\cline { 2 - 5 } & 0 & 33 & 67 & 100 & & P $\leq$ \\
\hline Peso vivo ao abate em jejum (kg) & 28,6 & 27,7 & 28,4 & 28,9 & 9,68 & $\hat{y}=28,4 \pm 2,70$ & - \\
Peso do corpo vazio (kg) & 24,3 & 23,4 & 23,9 & 23,6 & 10,6 & $\hat{y}=23,8 \pm 2,45$ \\
Peso da carcaça quente (kg) & 13,9 & 13,3 & 13,5 & 13,4 & 10,2 & $\hat{y}=13,5 \pm 1,34$ & - \\
Peso da carcaça fria (kg) & 13,6 & 13,0 & 13,3 & 13,1 & 10,1 & $\hat{y}=13,2 \pm 1,30$ & - \\
Rendimento de carcaça quente (\%) & 48,8 & 47,8 & 47,7 & 46,2 & 2,71 & $\hat{y}=48,8-0,02 \mathrm{TMD} ; \mathrm{r}^{2}=0,35$ & 0,0072 \\
Rendimento de carcaça fria (\%) & 47,5 & 46,8 & 46,9 & 45,3 & 2,61 & $\hat{y}=47,6-0,02 \mathrm{TMD} ; \mathrm{r}^{2}=0,31$ & 0,0132 \\
Rendimento biológico (\%) & 57,4 & 56,8 & 56,6 & 56,6 & 1,65 & $\hat{y}=56,8 \pm 0,92$ & - \\
\hline
\end{tabular}


Medeiros et al. (2007) em carcaças de cordeiros Morada Nova abatidos aos 30,9 kg. Essa variação de resultados está relacionada possivelmente ao tipo de alimento fornecido e à idade dos animais.

O peso da costela e os rendimentos da costela e da paleta foram influenciados $(\mathrm{P}<0,05)$ de forma linear e decrescente pelos níveis de substituição do farelo de soja pela torta de mamona (Tabela 5), enquanto o peso e o rendimento das demais regiões não sofreram efeito $(\mathrm{P}>0,05)$ dos níveis de substituição. A perna foi o corte mais pesado e com melhor rendimento percentual, pois possui maior musculosidade e maior rendimento da parte comestível (Silva Sobrinho, 2001).

Em análise dos dados observados, verificaram-se diferenças numéricas mínimas entre os pesos dos cortes para cada nível de substituição, o que sugere constância desses valores, uma vez que o abate dos animais ocorreu quando a média de peso em cada tratamento atingiu $30 \mathrm{~kg}$. Essa similaridade de pesos reforça a lei da harmonia anatômica (Boccard \& Dumont, 1960). Medeiros et al. (2007) relataram pesos de 2,05 kg para a perna; $0,639 \mathrm{~kg}$ para lombo; 1,18 kg para paleta e 0,681 kg para o pescoço de ovinos Morada Nova alimentados com dietas contendo 50\% de concentrado, enquanto Gonzaga Neto et al. (2006) relataram pesos de 1,75 kg para perna; $0,67 \mathrm{~kg}$ para lombo; $1,06 \mathrm{~kg}$ para a paleta e $0,51 \mathrm{~kg}$ para o pescoço de ovinos Morada Nova alimentados com dietas contendo $60 \%$ de concentrado.

Considerando o rendimento dos cortes e sua valorização comercial, observou-se efeito linear positivo $(\mathrm{P}<0,05)$ dos níveis de substituição do farelo de soja pela torta de mamona destoxificada sobre os cortes considerados de primeira (pernil + lombo), estimados em 51,1 e 53,1\%, respectivamente da carcaça fria. Esse resultado não era esperado, já que não foi observado efeito dos níveis de substituição sobre o rendimento da perna e do lombo. Para o rendimento dos cortes de terceira, que incluem costelas, peito, fraldinha e pescoço, não foi observado efeito $(\mathrm{P}>0,05)$ dos níveis de substituição do farelo de soja pela torta de mamona, com média igual a 29,3\%. Valores próximos aos encontrados neste estudo foram relatados por Zapata et al. (2001), que citaram para ovinos Morada Nova da variedade branca valores entre 32,2 e 32,7\% para pernil; 19,9 e 21,4\% para paleta; e 10,3 e $11,1 \%$ para lombo, em relação à carcaça fria.

Os resultados desta pesquisa revelam, de forma geral, que os cortes de maior importância comercial têm significativa participação na carcaça, representando mais de $50 \%$ de sua composição, considerando apenas a perna e o lombo (cortes de primeira categoria) e atingindo mais de $70 \%$ com a incorporação da paleta, corte de segunda categoria, mas bastante valorizado pelo consumidor.

Tabela 5 - Rendimento de cortes de ovinos mestiços Morada Nova $\times$ SPRD alimentados com dietas contendo torta de mamona destoxificada em substituição ao farelo de soja

\begin{tabular}{|c|c|c|c|c|c|c|c|}
\hline \multirow[t]{2}{*}{ Corte } & \multicolumn{4}{|c|}{ Nível de substituição (\%MS) } & \multirow[t]{2}{*}{$\mathrm{CV}(\%)$} & \multirow[t]{2}{*}{ Equação } & \multirow[t]{2}{*}{$\mathrm{P} \leq$} \\
\hline & 0 & 33 & 67 & 100 & & & \\
\hline Peso da meia-carcaça (kg) & 6,76 & 6,33 & 6,62 & 6,51 & 9,80 & $\hat{y}=6,55 \pm 0,63$ & - \\
\hline Perna (kg) & 2,13 & 1,96 & 2,05 & 2,05 & 8,98 & $\hat{y}=2,05 \pm 0,18$ & - \\
\hline Lombo anterior (kg) & 0,952 & 0,902 & 1,02 & 0,988 & 12,5 & $\hat{y}=0,964 \pm 0,12$ & - \\
\hline Lombo posterior (kg) & 0,370 & 0,392 & 0,394 & 0,388 & 18,6 & $\hat{y}=0,386 \pm 0,08$ & - \\
\hline Paleta（kg） & 1,31 & 1,20 & 1,25 & 1,17 & 10,6 & $\hat{y}=1,23 \pm 0,13$ & - \\
\hline Costela (kg) & 0,436 & 0,356 & 0,354 & 0,328 & 16,2 & $\hat{y}=0,417-0,001 \mathrm{TMD} ; \mathrm{r}^{2}=0,29$ & 0,0139 \\
\hline Peito (kg) & 0,424 & 0,344 & 0,388 & 0,394 & 24,4 & $\hat{y}=0,387 \pm 0,09$ & - \\
\hline Fraldinha (kg) & 0,608 & 0,614 & 0,602 & 0,612 & 16,3 & $\hat{y}=0,609 \pm 0,09$ & - \\
\hline Pescoço (kg) & 0,532 & 0,554 & 0,568 & 0,580 & 15,8 & $\hat{y}=0,559 \pm 0,09$ & - \\
\hline Perna (\%) & 31,5 & 31,1 & 30,9 & 31,5 & 2,29 & $\hat{y}=31,3 \pm 0,74$ & - \\
\hline Lombo anterior (\%) & 14,1 & 14,3 & 15,3 & 15,2 & 8,02 & $\hat{y}=14,7 \pm 1,15$ & - \\
\hline Lombo posterior (\%) & 5,44 & 6,19 & 5,98 & 5,90 & 15,3 & $X=5,88 \pm 0,90$ & - \\
\hline Paleta (\%) & 19,3 & 18,9 & 18,9 & 18,1 & 3,37 & $\hat{y}=19,4-0,01 \mathrm{TMD} ; \mathrm{r}^{2}=0,34$ & 0,0072 \\
\hline Costela (\%) & 6,42 & 5,60 & 5,36 & 4,98 & 11,4 & $\hat{y}=6,27-0,01 \mathrm{TMD} ; \mathrm{r}^{2}=0,42$ & 0,0021 \\
\hline Peito (\%) & 6,37 & 5,39 & 5,90 & 6,06 & 22,8 & $\hat{y}=5,93 \pm 1,35$ & - \\
\hline Fraldinha (\%) & 9,01 & 9,66 & 9,02 & 9,35 & 9,81 & $\hat{y}=9,26 \pm 0,89$ & - \\
\hline Pescoço (\%) & 7,87 & 8,81 & 8,57 & 8,91 & 14,0 & $\hat{y}=8,54 \pm 1,17$ & - \\
\hline Cortes de primeira ${ }^{1}$ & 51,0 & 51,6 & 52,3 & 52,6 & 2,63 & $\hat{y}=51,1+0,02 \mathrm{TMD} ; \mathrm{r}^{2}=0,20$ & 0,0408 \\
\hline Cortes de segunda ${ }^{2}$ & 19,3 & 18,9 & 18,9 & 18,1 & 3,37 & $\hat{y}=19,4-0,01 T M D ; r^{2}=0,36$ & 0,0072 \\
\hline Cortes de terceira $^{3}$ & 29,7 & 29,5 & 28,9 & 29,3 & 5,31 & $\hat{y}=29,3 \pm 1,52$ & - \\
\hline
\end{tabular}

1 Cortes de primeira categoria: perna e lombo (anterior e posterior).

2 Cortes de segunda categoria: paleta.

${ }^{3}$ Cortes de terceira categoria: costelas, peito, fraldinha e pescoço (Furusho-Garcia et al., 2004; Yamamoto et al., 2004). 


\section{Conclusões}

A torta de mamona destoxificada pelo método da autoclavagem tem potencial para ser utilizada em dietas para ovinos em terminação e podem ser adicionada em níveis de até $67 \%$ de substituição ao farelo de soja. A torta de mamona destoxificada não influencia as características de carcaça de ovinos.

\section{Referências}

ANANDAN, S.; ANIL KUMAR, G.K.; GHOSH, J. et al. Effect of different physical and chemical treatments on detoxification of ricin in castor cake. Animal Feed Science and Technology, v.120, n.1, p.159-168, 2005.

ASLANI, M.R.; MALEKI, M.; MOHRI, M. et al. Castor bean (Castor bean (Ricinus communis) toxicosis in sheep flock. Toxicon, v.49, n.1, p.400-406, 2006.

BOCCARD, R.; DUMONT, B.L. Étude de la production de la viande chez les ovins. II. Variation de l'importance relative des différentes régions corporelles de l'agneau de boucherie. Annales de Zootechnie, v.9, n.4, p.355-365, 1960.

FURUSHO-GARCIA, I.F.F.; PÉREZ, J.R.O.; BONAGURIO, S. et al. Desempenho de cordeiros Santa Inês puros e cruzas Santa Inês com Texel, Ile de France e Bergamácia. Revista Brasileira de Zootecnia, v.33, n.6, p.1591-1603, 2004.

GETTY, R. Anatomia dos animais domésticos. 5.ed. Rio de Janeiro: Guanabara-Koogan, 1986. v.1. 952p.

GOMES, F.H.T. Composição químico-bromatológica e degradação in situ de nutrientes de co-produtos da mamona e do pinhão-manso da cadeia produtiva do biodiesel. 2007. 49f. Monografia (Graduação em Agronomia) - Universidade Federal do Ceará, Fortaleza.

GONZAGA NETO, S.; SILVA SOBRINHO, A.G.; ZEOLA, N.M.B.L. et al. Características quantitativas da carcaça de cordeiros deslanados Morada Nova em função da relação volumoso: concentrado na dieta. Revista Brasileira de Zootecnia, v.35, n.4, p.1487-1495, 2006.

MEDEIROS, G.R.; CARVALHO, F.F.R.; BATISTA, A.M.V. et al. Efeito dos níveis de concentrado sobre as características de carcaça de ovinos Morada Nova em confinamento. Revista Brasileira de Zootecnia, v.38, n.4, p.718-727, 2007.

MONTE, A.L.S.; VASCONCELOS, P.M.; CORREIA, L.S. et al. Composição centesimal e mineral da carne de cabritos mestiços. Higiene Alimentar, v.23, p.134-137, 2009.

MOSHKIN, V.A. Castor. New Delhi: Amerind, 1986. 315p.
NATIONAL RESEARCH COUNCIL - NRC. Nutrient requirements of the dairy cattle. 7.ed. Washington, D.C.: National Academy of Sciences, 2001. 363p.

NATIONAL RESEARCH COUNCIL - NRC. Nutrient requirements of small ruminants. New York: National Academy of Sciences, 2007. 362p.

OLIVEIRA, A.S.; CAMPOS, J.M.S.; OLIVEIRA, M.R.C. et al. Nutrient digestibility, nitrogen metabolism and hepatic function of sheep fed diets containing solvent or expeller castorseed meal treated with calcium hydroxide. Animal Feed Science and Technology, v.158, n.1, p.15-28, 2010.

POMPEU, R.C.F.F; CÂNDIDO, M.J.D.; NEIVA, J.N.M. et al. Desempenho de ovinos em capim-tanzânia sob lotação rotativa com quatro proporções de suplementação concentrada. Arquivo Brasileiro de Medicina veterinária e Zootecnia, v.61, n.5, p.1104-1111, 2009.

SAÑUDO, C.; SIERRA, I. Calidad de la canal en la especie ovina. Ovino, n.1, p.127-157, 1986.

SILVA, L.F.; PIRES, C.C. Avaliações quantitativas das proporções de osso, músculo e gordura da carcaça em ovinos. Revista Brasileira de Zootecnia, v.29, n.4, p.1253-1260, 2000.

SILVA, D.J.; QUEIROZ, C. Análise de alimentos (métodos químicos e biológicos). Viçosa, MG: Universidade Federal de Viçosa, 2002. 235p.

SILVA SOBRINHO, A.G. Aspectos quantitativos e qualitativos da produção de carne ovina. In: MATTOS, W.R.S.; FARIA, V.P.; SILVA, S.C. et al. (Eds.) A produção animal na visão dos brasileiros. Piracicaba: Fundação de Estudos Agrários, 2001. p.425-460.

SNIFFEN, C.J.; O' CONNOR, J.D.; VAN SOEST, P.J. et al. A net carbohydrate and protein system for evaluation catlle diets. II. Carbohydrate and protein availability. Journal of Animal Science, v.70, p.3562-3577, 1992.

TOKARNIA, C.H.; DÖBEREINER, J.; PEIXOTO, P.V. Plantas tóxicas do Brasil. Rio de janeiro: Helianthus, 2000. 320p.

VIEIRA, M.M.M. Desempenho bioeconômico de ovinos alimentados com rações contendo farelo de mamona destoxificado. 2009. 87f. Dissertação (Mestrado em Zootecnia) - Universidade Federal do Ceará, Fortaleza.

VIEIRA, M.M.M.; CÂNDIDO, M.J.D.; BOMFIM, M.A.D. et al. Características da carcaça e dos componentes não-carcaça em ovinos alimentados com rações à base de farelo de mamona. Revista Brasileira de Saúde e Produção Animal, v.11, p.140-149, 2010.

YAMAMOTO, S.M.; MACEDO, F.A.F.; MEXIA, A.A. et al. Rendimentos dos cortes e não-componentes das carcaças de cordeiros terminados com dietas contendo diferentes fontes de óleo vegetal. Ciência Rural, v.34, n.6, p.1909-1913, 2004.

ZAPATA, J.FF.; SEABRA, L.M.A.J.; NOGUEIRA, C.M. et al. Características de carcaça de pequenos ruminantes do Nordeste do Brasil. Revista Ciência Animal, v.11, n.2, p.79-86, 2001. 